\title{
Sleep-apnea risk and subclinical atherosclerosis in early-middle-aged retired National Football League players
}

\author{
Faith S Luyster' \\ Reginald E Dunn² \\ Diane S Lauderdale ${ }^{3}$ \\ Mercedes R Carnethon ${ }^{4}$ \\ Andrew M Tucker ${ }^{5}$ \\ Robert A Vogel ${ }^{6}$ \\ Andrew E Lincoln ${ }^{2}$ \\ Kristen L Knutson ${ }^{7}$ \\ Elliot J Pellman ${ }^{8-10}$ \\ Patrick J Strollo Jr'l \\ 'School of Nursing, University of \\ Pittsburgh, Pittsburgh, PA, ${ }^{2}$ Sports \\ Medicine Research Center, MedStar \\ Health Research Institute, Baltimore, \\ MD, ${ }^{3}$ Department of Public Health \\ Sciences, University of Chicago, \\ ${ }^{4}$ Department of Preventive Medicine, \\ Northwestern University, Chicago, IL, \\ ${ }^{5}$ MedStar Sports Medicine, MedStar \\ Union Memorial Hospital, Baltimore, \\ MD, ${ }^{6}$ Cardiology Section, Department \\ of Veterans Affairs Medical Center, \\ Denver, CO, ${ }^{7}$ Department of Medicine, \\ University of Chicago, Chicago, IL, \\ ${ }^{8}$ ProHealth Care Associates, Lake \\ Success, ${ }^{9}$ Department of Medicine, \\ ${ }^{10}$ Department of Orthopedics, Mount \\ Sinai School of Medicine, New York, \\ NY, "Department of Pulmonary, \\ Allergy, and Critical Care Medicine, \\ University of Pittsburgh Medical \\ Center, Pittsburgh, PA, USA
}

Correspondence: Faith S Luyster School of Nursing, University of Pittsburgh, Room 415, 3500 Victoria Street, Pittsburgh, PA I526I, USA

$\mathrm{Tel}+14126247910$

Fax + I 4I23837293

Email luysterfs@upmc.edu
This article was published in the following Dove Press journal:

Nature and Science of Sleep

21 February 2017

Number of times this article has been viewed

Purpose: Limited data from former National Football League (NFL) players suggest that obstructive sleep apnea (OSA) may be highly prevalent after retirement. It remains unclear whether the high prevalence of OSA in retired players is comparable to nonathletes. This retrospective analysis compared sleep apnea (SA) risk in retired NFL players to a community cohort (CARDIA Sleep study), and examined associations between SA risk and cardiovascular risk factors, including subclinical atherosclerosis.

Materials and methods: Retired NFL players $(n=122)$ were matched to CARDIA Sleep participants by age \pm 2 years (range $37-55$ years), body mass index $\pm 2 \mathrm{~kg} / \mathrm{m}^{2}$, race, and male sex. Participants underwent electron-beam computed tomography to measure coronary artery calcium (CAC) and completed the Berlin Questionnaire to determine SA risk. The presence of CAC was defined as an Agatston score $>0$.

Results: Retired NFL players had a greater prevalence of high SA risk than the matched CARDIA Sleep participants ( $27 \%$ vs $11.5 \%, P=0.002)$. Compared to the CARDIA Sleep participants, retired players were less likely to smoke, and had higher blood pressure, lower fasting glucose levels, and higher cholesterol levels. However, there was no difference in the prevalence of detectable CAC ( $30 \%$ vs $30 \%, P=1)$. In both players and the community cohort, SA risk was not significantly associated with CAC after controlling for age, race, and body mass index.

Conclusion: Retired NFL players have a greater prevalence of high SA risk but similar prevalence of CAC compared with a well-matched community cohort.

Keywords: sleep apnea, cardiovascular risk, coronary artery calcium, national football league

\section{Introduction}

Professional American football players, particularly linemen, have a high prevalence of obesity, as determined by body mass index (BMI). ${ }^{1}$ After retirement, there is an increased likelihood of nonlinemen becoming obese, with up to $50 \%$ having a BMI $\geq 30$ $\mathrm{kg} / \mathrm{m}^{2} 25$ years after retirement. ${ }^{2}$ Obesity is a strong predictor of multiple medical conditions, including cardiovascular disease, hypertension, metabolic syndrome, diabetes, and obstructive sleep apnea (OSA). ${ }^{3-5}$ Independently of obesity, OSA is associated with cardiovascular mortality and morbidity. ${ }^{6-8}$ Prior research evaluating OSA among active National Football League (NFL) players found modest prevalence rates (14\%-19\%) of predominately mild-to-moderate OSA, particularly among players considered to be at high risk for OSA. ${ }^{9,10}$ Limited data from retired NFL players suggest that OSA may be more prevalent after retirement, possibly due to increasing proportions of players becoming obese. ${ }^{11}$ It remains unclear whether the high prevalence of OSA in retired players is comparable to nonathletes. In the present study, we compared sleep apnea 
(SA) risk in early-middle-aged retired NFL players to a community cohort matched on age, BMI, and race. Data were stratified by playing position to explore potential differences in SA risk. We also examined the associations between SA risk and cardiovascular risk factors, including subclinical atherosclerosis measured by coronary artery calcium (CAC), in both the retired NFL players and the community cohort. We expected to find similarities in the effect of SA risk on cardiovascular risk factors, in particular CAC, between the retired players and the community cohort.

\section{Materials and methods Subjects}

Multicity health screenings for retired NFL players were conducted as part of the NFL Player Care Foundation Cardiovascular Health Screening Program, directed by the NFL Subcommittee on Cardiovascular Health. Data from screenings performed in 2007-2012 $(n=1,422)$ were analyzed in this report. All players provided written informed consent prior to undergoing screening, according to a protocol approved by the institutional review board of MedStar Research Health Institute, Hyattsville, MD. At the time of screening, height, weight, and blood pressure (BP) were recorded for each player. Three consecutive BP readings were obtained, and the second and third readings were averaged. BMI was calculated as weight in kilograms divided by the square of height in meters. Waist circumference was measured. Information on position played, self-reported medical conditions, race, age, and smoking was collected. Smoking status was categorized as current or former smoker or nonsmoker. Diabetes was defined as a fasting blood glucose level $\geq 126 \mathrm{mg} / \mathrm{dL}$ or a previous diagnosis. Hypertension was defined as systolic $\mathrm{BP} \geq 140 \mathrm{mmHg}$, diastolic $\mathrm{BP} \geq 90 \mathrm{mmHg}$, or a previous diagnosis. A fasting venous blood sample was collected from each player. Total cholesterol, high-density lipoprotein (HDL) cholesterol, and triglycerides were measured using enzymatic techniques. Low-density lipoprotein (LDL) cholesterol was calculated using the Friedewald equation. ${ }^{12}$

CARDIA is an ongoing, multicenter-cohort study of cardiovascular risk development in young adults from the general population. The CARDIA cohort $(n=5,116)$ was recruited from four study sites in 1985-1986, and included a sample of adults aged 18-30 years balanced by sex, race (white and black), and education. A detailed study description is available elsewhere. ${ }^{13}$ The comparison cohort for the current analyses was selected from participants in an ancillary sleep study (CARDIA Sleep; $n=669$ ). Participants were recruited from one CARDIA site, and participated in the sleep study in 2003 and 2004. For each retired NFL player, one man was randomly selected of age \pm 2 years, BMI \pm 2 , and the same race.

\section{Data collection}

During clinical examination in year 20 of CARDIA (20052006), baseline questionnaires obtained information on demographic characteristics and smoking. Smoking status was categorized the same as for the retired players. BP readings were collected in the same manner as for the players. ${ }^{13}$ Hypertension and diabetes were defined the same as for the retired players. As described previously, ${ }^{14}$ plasma total and lipoprotein cholesterol concentrations were measured using an enzymatic assay by Northwest Lipids Research Laboratory (Seattle, WA, USA). LDL cholesterol was calculated using the Friedewald equation. ${ }^{12}$

\section{Assessment of SA risk}

SA risk was assessed by the Berlin Questionnaire ${ }^{15}$ in both the retired NFL players and the CARDIA Sleep cohort. The Berlin Questionnaire categorizes individuals as having high risk for SA if they have two of the following three conditions: 1) loud or frequent snoring or witnessed apneas, 2) frequent sleepiness and fatigue after sleep or during wake time or having fallen asleep while driving, or 3) having a history of hypertension or a BMI $>30$. Sleep duration was assessed among the retired NFL players using the question "How many hours do you sleep during a 24-hour period?" Responses were on a 7-point Likert scale, from $1=$ "5 hours or less" to $7=$ " 11 hours or more". CARDIA Sleep participants provided their response to the following item during the CARDIA year-20 examination: "During the past month, how many hours of actual sleep did you get at night? (This may be different than the number of hours you spent in bed)."

\section{Measurement of coronary artery calcium}

CAC scanning was performed within 1 week of the screening visit for each retired player. A modified Agatston protocol ${ }^{16}$ was used at each site, and most sites had one designated reader. CAC scores were expressed in Agatston units, with a CAC score $>0$ indicating the presence of CAC. In the CARDIA Sleep cohort, two CAC scans were performed at the year-20 assessment using electron-beam computed tomography, as previously described. ${ }^{17}$ The reader identified a region of interest for each potential focus of CAC, defined as four or more adjacent pixels $\left(1.87 \mathrm{~mm}^{2}\right)$ with a computed tomography number $>130 \mathrm{HU}$ (field of view $35 \mathrm{~cm}$ ). Agatston scores were adjusted for between-center differences using a 
standard calcium phantom scanned underneath each participant, and summed across the four major coronary arteries to compute a total calcium score. ${ }^{16}$ The presence of CAC was defined as having a positive, non-0 Agatston score, using an average of two scans. CAC scores were also grouped by 0 , $1-99$, and $\geq 100$.

\section{Statistical analysis}

Statistical analyses were performed using IBM SPSS version 22. Data are presented as means \pm standard deviation or number (percentage). Student's $t$-test was used to analyze group differences for continuous variables, and $\chi^{2}$ tests or Fisher's exact test (if the number in any cell was fewer than five) were employed for categorical variables. Linemen versus nonlinemen group differences were compared the same way. To evaluate the associations between SA risk and cardiovascular risk factors by group (retired NFL player vs community cohort), presence of hypertension, fasting glucose levels, cholesterol levels, and presence of CAC were used as outcome variables in multivariable linear and logistic regression models. Multiplicative interactions were tested by adding an interaction term of "SA risk and group" in a model that also included their main effects. All models were fitted both with and without adjustment for age, BMI, and race.

\section{Results}

Of the 1,422 retired NFL players who underwent screenings in 2007-2012, 1,238 completed CAC imaging. There were 55 players who did not self-identify as white or black (18 Asian, 37 missing). Since the CARDIA Sleep cohort was comprised of whites and blacks, the retired NFL sample was restricted to whites and blacks. A total of 110 retired players fell short of the lower age of the range (ie, 37 years old) of the CARDIA Sleep cohort, and 648 exceeded the upper age of the range (ie, 55 years old). A total of 22 retired players had a missing BMI value, and 972 had missing data on the Berlin Questionnaire. Those with missing Berlin Questionnaire data had higher lipid concentrations, except for triglycerides, and lower prevalence of CAC compared to those without missing data. There were 193 retired NFL players available for matching (see Figure 1).

The ancillary sleep study included 669 participants recruited from CARDIA who participated in the year 15 (2000-2001) clinical examination. Of these 669 participants, 284 were males. A total of 238 male participants completed CAC imaging at year 20 (2005-2006). Seventeen participants were missing data on the Berlin Questionnaire. There were 221 male participants from the CARDIA Sleep cohort

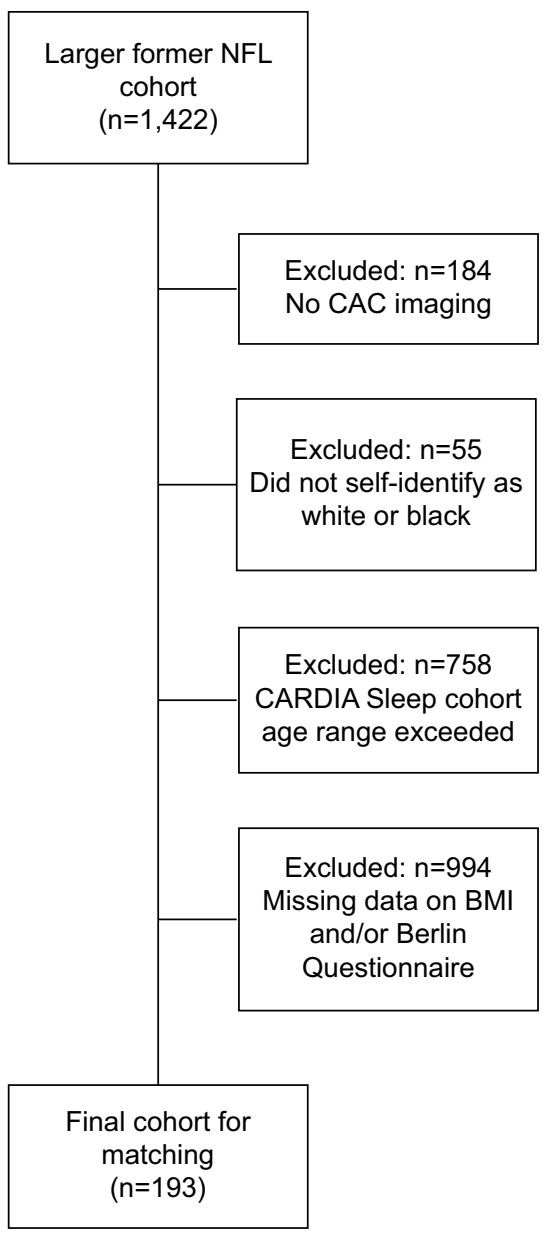

Figure I Participant flowchart.

Abbreviations: NFL, National Football League; CAC, coronary artery calcium; BMI, body mass index.

available for matching (see Figure 2). By age, BMI, and race, 122 CARDIA Sleep cohort participants were matched with 122 retired NFL players.

Table 1 displays the baseline characteristics of the retired NFL players matched to the CARDIA Sleep cohort for age, BMI, and race. The retired NFL players had higher systolic and diastolic BP and higher total, LDL, and HDL cholesterol levels than the CARDIA Sleep cohort. Compared to the retired players, the CARDIA Sleep cohort had a higher prevalence of former/current smokers and higher fasting glucose levels. The two groups were not statistically different in triglycerides, presence of hypertension and diabetes, or sleep duration. Cardiovascular risk profiles were similar between former linemen and nonlinemen (Table 2).

There was a significantly greater percentage of retired players at high risk for SA compared with the CARDIA Sleep cohort (27\% vs $11.5 \%$, respectively; $P=0.002$; Table 1 ). Former players reported significantly more snoring that bothered others $(P=0.001)$ and more frequent snoring $(P<0.001)$ than 


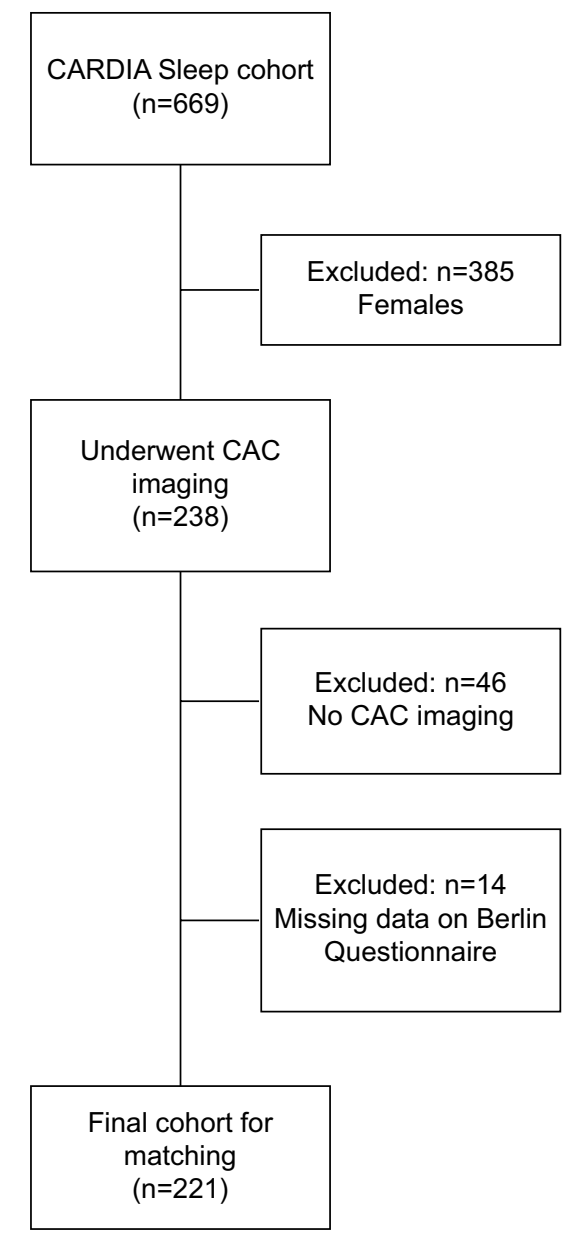

Figure 2 Participant flowchart.

Abbreviation: CAC, coronary artery calcium.

the comparison group (Tables 3 and 4). The CARDIA Sleep cohort reported significantly more frequent daytime sleepiness ( $P=0.04$; Table 3 ). Nonlinemen had a greater prevalence of high SA risk than linemen, although this difference only approached significance ( $33 \%$ vs $15 \%$, respectively, $\chi^{2}=3.6$; $P=0.06$; Table 2).

The prevalence of CAC was the same for retired players $(30 \%)$ and the CARDIA Sleep cohort (30\%; $P=1$; Table 1$)$. Additionally, there was no difference in the distribution of CAC scores. Nonlinemen and lineman were not significantly different in prevalence of CAC ( $33 \%$ vs $24 \%$, respectively; $P=0.31$; Table 2).

In multivariable linear and logistic regression analyses adjusted for age, BMI, and race, no significant association between SA risk and presence of CAC was found among the retired players or the community cohort (OR $2.07,95 \% \mathrm{CI}$ 0.8-5.33; OR 2.71, 95\% CI 0.8-9.19; respectively; Table 5). Among retired players, those with high SA risk had higher systolic BP compared to those with low SA risk $(\beta=0.21$, $P=0.03$; Table 5). Among the CARDIA Sleep cohort, SA risk was not significantly associated with any of the other cardiovascular risk factors. The formal tests of interaction between group (NFL versus CARDIA) and SA risk in relation to the cardiovascular risk factors were not statistically significant.

\section{Discussion}

This is the first study to compare SA risk in early-middleaged retired NFL players to an age-, BMI-, and race-matched community-based cohort. Despite similar rates of obesity, as defined by BMI criteria, the prevalence of high SA risk in the early-middle-aged retired players was over twice that found in the CARDIA Sleep cohort. Data on OSA in retired professional football players are limited, but as in the current study, the findings suggest an increased prevalence of OSA in these former athletes. ${ }^{11}$ In a sample of 257 retired NFL players (mean age 54 years), $52 \%$ were found to have an apnea-hypopnea index score $\geq 10$ based on portable monitoring, and BMI was found to be a significant predictor of OSA. ${ }^{11}$ The greater prevalence of high SA risk among the retired players compared to the CARDIA Sleep comparison group was driven by more frequent snoring and snoring that bothered others, which have been shown to be common OSA symptoms among active NFL players. ${ }^{10}$

The retired players and the matched cohort had differing cardiovascular risk-factor profiles, with the exception of triglycerides and presence of hypertension and diabetes. The prevalence of CAC was approximately a third in both samples. This finding is consistent with previous studies evaluating subclinical atherosclerosis in retired players that found no differences in carotid artery plaques or CAC between former players (mean age 51 years) and a community cohort of similar age and BMI. ${ }^{18,19}$ The increased prevalence of high SA risk and higher BP among the retired players and the higher prevalence of smoking in the CARDIA Sleep cohort could have balanced out any differences in CAC prevalence between these groups. Our findings and those of prior studies suggest that retired NFL players with high BMI are at the same increased risk for cardiovascular risk factors as obese nonathletes. ${ }^{18,19}$

In our stratified analysis by player position, retired nonlinemen had a greater prevalence of high SA risk compared to linemen. Although this difference in prevalence of SA risk was not significantly different (borderline significance at $P=0.06$ ), it may be a clinically meaningful difference. In a previous study examining OSA in retired players, linemen were more likely to have OSA and obesity than nonlinemen. ${ }^{11}$ In our retired NFL sample, linemen and nonlinemen 
Table I Demographic and cardiovascular risk characteristics of retired professional football players and CARDIA Sleep cohort

\begin{tabular}{|c|c|c|c|c|c|}
\hline \multirow[t]{2}{*}{ Variables } & \multicolumn{2}{|c|}{$\begin{array}{l}\text { Retired professional football } \\
\text { players }(n=122)\end{array}$} & \multicolumn{2}{|c|}{$\begin{array}{l}\text { CARDIA Sleep cohort } \\
(n=122)\end{array}$} & \multirow[t]{2}{*}{$P$-value* } \\
\hline & $\mathbf{n}$ & Value & $\mathbf{n}$ & Value & \\
\hline Age (years) & 122 & $45.3 \pm 4.2$ & 122 & $45.3 \pm 3.6$ & - \\
\hline Black & 122 & $5 \mathrm{I}(4 \mathrm{I} .8 \%)$ & 122 & $5 \mathrm{I}(4 \mathrm{I} .8 \%)$ & - \\
\hline Current/former smokers & 122 & $9(7.3 \%)$ & 68 & $4 \mathrm{I}(60.3 \%)$ & $<0.001$ \\
\hline Years since retirement ${ }^{a}$ & 53 & $20.3 \pm 6.3$ & - & - & - \\
\hline Waist circumference $(\mathrm{cm})$ & 122 & $95.2 \pm 22$ & 122 & $98.1 \pm 10.2$ & 0.19 \\
\hline BMI $\left(\mathbf{k g} / \mathbf{m}^{2}\right)$ & 122 & $30.3 \pm 3.8$ & 122 & $29.9 \pm 4$ & - \\
\hline Obese $(\mathrm{BMI} \geq 30)$ & 122 & 60 (49.2\%) & 122 & $5 \mathrm{I}(4 \mathrm{I} .8 \%)$ & 0.25 \\
\hline Hypertension ${ }^{b}$ & 122 & $36(29.5 \%)$ & 122 & $35(28.7 \%)$ & 0.89 \\
\hline \multicolumn{6}{|l|}{$\mathrm{BP}, \mathrm{mmHg}$} \\
\hline Systolic & 122 & $125.3 \pm 13.9$ & 122 & $120.4 \pm 13.2$ & 0.005 \\
\hline Diastolic & 122 & $80.1 \pm 10.3$ & 122 & $75.0 \pm 11.2$ & $<0.001$ \\
\hline \multicolumn{6}{|l|}{ Lipids, mg/dL } \\
\hline HDL-C & 108 & $49.9 \pm 11.5$ & 122 & $44.9 \pm 12$ & 0.001 \\
\hline LDL-C & 107 & $126.5 \pm 39.7$ & 118 & $\mid 10.5 \pm 31.7$ & 0.001 \\
\hline Total cholesterol & 108 & $197.9 \pm 43.5$ & 122 & $183.4 \pm 35.9$ & 0.006 \\
\hline Triglycerides & 108 & $140.3 \pm 96.5$ & 122 & $140.2 \pm 92.4$ & 0.05 \\
\hline Diabetes $^{c}$ & 116 & $9(7.8 \%)$ & 122 & $8(6.7 \%)$ & 0.72 \\
\hline Fasting glucose, $\mathrm{mg} / \mathrm{dL}$ & 122 & $89.4 \pm 36.4$ & 122 & $101.7 \pm 19.6$ & 0.001 \\
\hline Sleep duration, hours & 116 & & 114 & & 0.06 \\
\hline$\leq 5$ & & $8(6.9 \%)$ & & $12(10.6 \%)$ & \\
\hline About 6 & & 45 (38.8\%) & & $46(40.3 \%)$ & \\
\hline About 7 & & $42(36.2 \%)$ & & $46(40.3 \%)$ & \\
\hline$\geq 8$ & & $21(18.1 \%)$ & & $10(8.8 \%)$ & \\
\hline Sleep-apnea risk & 122 & & 122 & & 0.002 \\
\hline Low & & 89 (73\%) & & 108 (88.5\%) & \\
\hline High & & $33(27 \%)$ & & 14 (II.5\%) & \\
\hline CAC presence & 122 & $37(30.3 \%)$ & 122 & $37(30.3 \%)$ & I \\
\hline CAC distribution & 122 & & 122 & & 0.95 \\
\hline 0 & & 87 (71.3\%) & & $87(71.3 \%)$ & \\
\hline I-99.99 & & $29(23.8 \%)$ & & $28(23 \%)$ & \\
\hline$\geq 100$ & & $6(4.9 \%)$ & & $7(5.7 \%)$ & \\
\hline
\end{tabular}

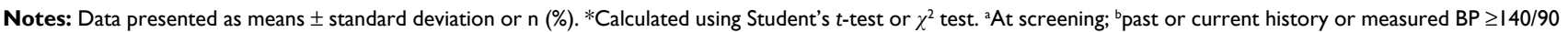

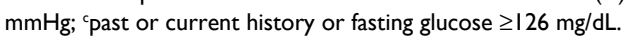

Abbreviations: BMI, body mass index; BP, blood pressure; HDL-C, high-density-lipoprotein cholesterol; LDL-C, low-density-lipoprotein cholesterol; CAC, coronary artery calcium.

both had similar rates of obesity. Following retirement, nonlinemen are likely to also become obese, as evidenced by Miller et $\mathrm{al}^{2}$ who found $50 \%$ of former nonlinemen to have a BMI $\geq 30$ an average of 25 years after retirement. No differences in cardiovascular risk factors were found between former linemen and nonlinemen in the current study, as may be expected given the similarity in BMI. Conversely, studies comparing cardiovascular risk factors in retired linemen to nonlinemen have found increased risk for hypertension ${ }^{11,19,20}$ and metabolic syndrome; ${ }^{2,20}$ however, linemen in these studies had higher BMI than nonlinemen. Consistently with our findings, no difference in prevalence of subclinical atherosclerosis was found between former linemen and nonlinemen. ${ }^{18,20}$

High SA risk was not significantly associated with the presence of hypertension, lipid and glucose concentrations, or CAC presence after adjustment for age, race, and BMI for the retired players and the community cohort. High SA risk was associated with higher systolic BP among the retired players. Our previous work in a community cohor $^{21}$ and studies in retired and active NFL players, ${ }^{10,11}$ demonstrating no significant relationship between OSA and cardiovascular risk factors after controlling for BMI, support our findings. Obesity is likely a confounder of the association between OSA and cardiovascular risk factors, including subclinical atherosclerosis, as it is an independent predictor of OSA $\mathrm{O}^{4,22}$ and cardiovascular morbidity. ${ }^{23,24}$ Sedentary activity as defined by $<30$ minutes of self-reported physical activity three times per week has been reported in a third of retired NFL players. ${ }^{18}$ Given the known health benefits of regular physical activity, ${ }^{25,26}$ promotion of continued physical activity after retirement will be essential for weight loss and weight 
Table 2 Demographic and cardiovascular risk characteristics of former linemen and nonlinemen

\begin{tabular}{|c|c|c|c|}
\hline Variables & $\begin{array}{l}\text { Linemen } \\
(n=34)\end{array}$ & $\begin{array}{l}\text { Nonlinemen } \\
(\mathrm{n}=\mathbf{8 8})\end{array}$ & $P$-value* \\
\hline Age (years) & $43.9 \pm 4$ & $45.9 \pm 4.1$ & 0.02 \\
\hline Black & 9 (26.4\%) & $42(47.7 \%)$ & 0.03 \\
\hline Current/former smokers & I (2.9\%) & $8(9.1 \%)$ & 0.24 \\
\hline Waist circumference $(\mathrm{cm})$ & $92.6 \pm 19.7$ & $96.2 \pm 22.8$ & 0.41 \\
\hline BMI $\left(\mathbf{k g} / \mathbf{m}^{2}\right)$ & $29.8 \pm 2.9$ & $30.5 \pm 4.1$ & 0.36 \\
\hline Obese (BMI >30) & $13(38.2 \%)$ & $47(53.4 \%)$ & 0.13 \\
\hline Hypertension $^{\mathrm{a}}$ & $9(26.5 \%)$ & 27 (30.7\%) & 0.65 \\
\hline \multicolumn{4}{|l|}{ BP, $\mathbf{m m H g}$} \\
\hline Systolic & $124.6 \pm 16.9$ & $125.6 \pm 12.7$ & 0.72 \\
\hline Diastolic & $81.4 \pm 9.7$ & $80 \pm 9.7$ & 0.37 \\
\hline \multicolumn{4}{|l|}{ Lipids, mg/dL } \\
\hline $\mathrm{HDL}-\mathrm{C}^{\mathrm{b}}$ & $47.9 \pm 11.9$ & $50.8 \pm 11.3$ & 0.24 \\
\hline LDL-C ${ }^{b}$ & $135 \pm 48.7$ & $122.9 \pm 34.9$ & 0.15 \\
\hline Total cholesterol ${ }^{\mathrm{b}}$ & $198.1 \pm 55.8$ & $197.9 \pm 37.6$ & 0.98 \\
\hline Triglycerides $^{c}$ & $105.3 \pm 75.1$ & $120.5 \pm 104.3$ & 0.46 \\
\hline Diabetes $^{\mathrm{b}, \mathrm{c}}$ & $2(5.9 \%)$ & 7 (8.5\%) & 0.63 \\
\hline Fasting glucose, $\mathrm{mg} / \mathrm{dL}$ & $91.5 \pm 20.2$ & $88.6 \pm 41.1$ & 0.7 \\
\hline Sleep duration, hours ${ }^{b}$ & & & 0.07 \\
\hline$\leq 5$ & 0 & $8(9.5 \%)$ & \\
\hline $6-6.5$ & $16(47 \%)$ & $29(34.5 \%)$ & \\
\hline $7-7.5$ & $8(23.5 \%)$ & 34 (40.5\%) & \\
\hline$\geq 8$ & $8(23.5 \%)$ & $13(15.5 \%)$ & \\
\hline Sleep-apnea risk & & & 0.06 \\
\hline Low & 29 (85.3\%) & 60 (7I.4\%) & \\
\hline High & 5 (I4.7\%) & $28(33.3 \%)$ & \\
\hline CAC presence & 8 (23.5\%) & $29(33.0 \%)$ & 0.31 \\
\hline
\end{tabular}

Notes: Data presented as means \pm standard deviation or $\mathrm{n}(\%)$. ${ }^{*}$ Calculated using Student's $t$-test or $\chi^{2}$ test. aPast or current history or measured blood pressure $\geq 140 / 90 \mathrm{mmHg}$; ${ }^{b}$ missing data for this variable; 'past or current history or fasting glucose $\geq 126 \mathrm{mg} / \mathrm{dL}$.

Abbreviations: BMI, body mass index; BP, blood pressure; HDL-C, high-densitylipoprotein cholesterol; LDL-C, low-density-lipoprotein cholesterol; CAC, coronary artery calcium.

maintenance among retired NFL players, and consequently reducing the risk of cardiovascular disease and the burden of OSA.

The current study has a number of limitations that should be taken into account when considering the results. The use of a self-reported screening tool for OSA without objective assessment, such as polysomnography, precludes confirmation that those individuals who scored in the highrisk range actually had OSA, and thus the proportion of high-risk participants identified by the Berlin Questionnaire may be overestimated or underestimated. A large number of retired players were excluded from the analyses, due to missing data, in particular on the Berlin Questionnaire, which may limit generalizability to the general population of retired players. However, retired players excluded from the analyses due to missing data on the Berlin Questionnaire had demographic and clinical characteristics similar
Table 3 Berlin Questionnaire responses of retired professional football players and CARDIA Sleep cohort

\begin{tabular}{|c|c|c|c|}
\hline \multicolumn{2}{|l|}{$\begin{array}{l}\text { Retired professional football } \\
\text { players }(n=122)\end{array}$} & $\begin{array}{l}\text { CARDIA Sleep } \\
\text { cohort }(n=122)\end{array}$ & $P$-value \\
\hline \multicolumn{4}{|l|}{ I. Do you snore? } \\
\hline Yes & $73(62.9 \%)$ & $76(62.3 \%)$ & 0.92 \\
\hline No/l don't know & $43(37.1 \%)$ & $46(37.7 \%)$ & \\
\hline \multicolumn{4}{|c|}{ 2. If you snore, your snoring is: } \\
\hline Slightly louder than breathing & $33(46.5 \%)$ & $32(40 \%)$ & 0.2 \\
\hline As loud as talking & $20(28.1 \%)$ & $34(42.5 \%)$ & \\
\hline Louder than talking & $7(9.9 \%)$ & $8(10 \%)$ & \\
\hline $\begin{array}{l}\text { Very loud - can be heard in } \\
\text { adjacent rooms }\end{array}$ & II (I5.5\%) & $6(7.5 \%)$ & \\
\hline \multicolumn{4}{|c|}{ 3. If you snore, how often do you snore? } \\
\hline Nearly every day & $25(35.7 \%)$ & $20(25 \%)$ & $<0.001$ \\
\hline 3-4 times a week & $27(38.7 \%)$ & $25(31.3 \%)$ & \\
\hline Once or twice a week & $18(25.7 \%)$ & $23(28.7 \%)$ & \\
\hline Once or twice a month & 0 & $10(12.5 \%)$ & \\
\hline Never or nearly never & 0 & $2(2.5 \%)$ & \\
\hline \multicolumn{4}{|c|}{ 4. Has your snoring ever bothered other people? } \\
\hline Yes & $50(72.5 \%)$ & $37(46.3 \%)$ & 0.001 \\
\hline No/l don't know & $19(27.5 \%)$ & $43(53.7 \%)$ & \\
\hline \multicolumn{4}{|c|}{$\begin{array}{l}\text { 5. Has anyone noticed that you quit breathing during } \\
\text { your sleep? }\end{array}$} \\
\hline Nearly every day & $4(3.6 \%)$ & $5(4.1 \%)$ & 0.96 \\
\hline 3-4 times a week & $3(2.7 \%)$ & $4(3.3 \%)$ & \\
\hline Once or twice a week & $7(6.3 \%)$ & $7(5.8 \%)$ & \\
\hline Once or twice a month & $9(8.1 \%)$ & $7(5.8 \%)$ & \\
\hline Never or nearly never & $88(79.3 \%)$ & $98(81 \%)$ & \\
\hline \multicolumn{4}{|c|}{ 6. How often do you feel tired or fatigued after your sleep? } \\
\hline Nearly every day & $8(6.7 \%)$ & $8(6.6 \%)$ & 0.25 \\
\hline 3-4 times a week & $18(15.1 \%)$ & $17(9.8 \%)$ & \\
\hline Once or twice a week & $18(15.1 \%)$ & $30(24.6 \%)$ & \\
\hline Once or twice a month & $31(26.1 \%)$ & $36(29.5 \%)$ & \\
\hline Never or nearly never & $44(37 \%)$ & $36(29.5 \%)$ & \\
\hline
\end{tabular}

7. During your waking time, do you feel tired, fatigued, or not up to par?

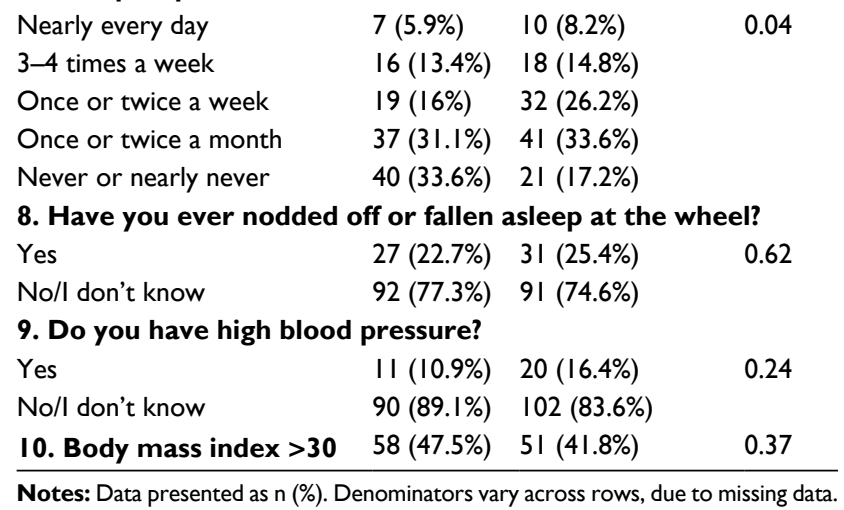

to the sample included in the analyses. The current study included early-middle-aged retired players (age 37-55 years), and thus the findings may not generalize to older retired players. Using BMI to determine obesity could have overestimated its prevalence in the retired NFL players if they had greater muscle mass relative to the general population. ${ }^{27}$ 
Table 4 Proportion with high risk in each category on the Berlin Questionnaire

\begin{tabular}{lll}
\hline $\begin{array}{l}\text { Retired professional } \\
\text { football players }(n=122)\end{array}$ & $\begin{array}{l}\text { CARDIA Sleep } \\
\text { cohort }(n=122)\end{array}$ & P-value \\
\hline
\end{tabular}

Category I Persistent symptoms ( $>3-4$ times per week) in two or more snoring questions

$$
35(28.7 \%) \quad 8(6.6 \%) \quad<0.001
$$

Category 2 Persistent ( $>3-4$ times per week) fatigue and/or daytime sleepiness

$$
19(15.6 \%) \quad 23(18.9 \%) \quad 0.50
$$

Category 3 History of hypertension or body mass index $>30$

$$
62(50.8 \%) \quad 59(48.4 \%) \quad 0.70
$$

In conclusion, early-middle-aged retired NFL players have a greater prevalence of high SA risk compared to a well-matched community cohort with similar rates of obesity. However, the prevalence of subclinical atherosclerosis evaluated by CAC was similar between the retired players and the community cohort. After controlling for age, BMI, and race, $\mathrm{SA}$ risk was not significantly associated with presence of CAC among the retired players and the community cohort. Further studies assessing OSA in retired NFL players and its cardiovascular consequences is needed.

\begin{tabular}{|c|c|c|c|c|}
\hline Group & Cardiovascular risk-factor outcome & $\beta(95 \% \mathrm{Cl}))$ & OR $(95 \% \mathrm{Cl})$ & Interaction P-value \\
\hline & Hypertension $^{a}$ & & & \\
\hline Total & & & $1.64(0.8 \mathrm{I}-3.32)$ & \\
\hline NFL & & & $1.87(0.75-4.64)$ & \\
\hline \multirow[t]{2}{*}{ CARDIA } & & & $1.94(0.55-6.78)$ & 0.96 \\
\hline & SBP, $\mathbf{m m H g}$ & & & \\
\hline Total & & $0.17(0.7-5.24)$ & & \\
\hline NFL & & $0.21(0.23-6.24)^{*}$ & & \\
\hline \multirow[t]{2}{*}{ CARDIA } & & $0.06(-2.59$ to 5$)$ & & 0.4 \\
\hline & DBP, $\mathbf{m m H g}$ & & & \\
\hline Total & & $0.12(-0.14$ to $3.5 \mathrm{I})$ & & \\
\hline NFL & & $0.15(-5.15$ to 3.98$)$ & & \\
\hline \multirow[t]{2}{*}{ CARDIA } & & $0.05(-2.23$ to 3.97$)$ & & 0.93 \\
\hline & Diabetes $^{b}$ & & & \\
\hline Total & & & $1.44(0.44-4.72)$ & \\
\hline NFL & & & $1.41(0.25-8.02)$ & \\
\hline \multirow[t]{2}{*}{ CARDIA } & & & $2.28(0.32-16.53)$ & 0.87 \\
\hline & Fasting glucose, $\mathrm{mg} / \mathrm{dL}$ & & & \\
\hline Total & & $0.06(-2.28$ to 6.01$)$ & & \\
\hline NFL & & $0.16(-0.84$ to II.7I) & & \\
\hline \multirow[t]{2}{*}{ CARDIA } & & $0.03(-4.35$ to 6.17$)$ & & 0.48 \\
\hline & Total cholesterol, mg/dL & & & \\
\hline Total & & $-0.04(-9.45$ to 5.18$)$ & & \\
\hline NFL & & $-0.12(-16.5$ to 4.5$)$ & & \\
\hline \multirow[t]{2}{*}{ CARDIA } & & $-0.03(-12.04$ to 9.02$)$ & & 0.89 \\
\hline & LDL cholesterol, mg/dL & & & \\
\hline Total & & $-0.1(-11.68$ to 1.72$)$ & & \\
\hline NFL & & $-0.2(-18.93$ to 0.2$)$ & & \\
\hline \multirow[t]{2}{*}{ CARDIA } & & $-0.06(-12.19$ to 6.45$)$ & & 0.6 \\
\hline & HDL cholesterol, mg/dL & & & \\
\hline Total & & 0.05 (-1.27 to 2.79$)$ & & \\
\hline NFL & & $-0.02(-2.83$ to 2.39$)$ & & \\
\hline \multirow[t]{2}{*}{ CARDIA } & & $0.04(-2.46$ to 4.04$)$ & & 0.68 \\
\hline & Triglycerides, $\mathrm{mg} / \mathrm{dL}$ & & & \\
\hline Total & & $0.07(-8.37$ to 25.01$)$ & & \\
\hline NFL & & $0.13(-7.23$ to 37.24$)$ & & \\
\hline \multirow[t]{2}{*}{ CARDIA } & & 0.02 (-23.88 to 28.82$)$ & & 0.42 \\
\hline & CAC presence & & & \\
\hline Total & & & $2.07(1.02-4.2)$ & \\
\hline NFL & & & $2.07(0.8-5.33)$ & \\
\hline CARDIA & & & $2.71(0.8-9.19)$ & 0.44 \\
\hline
\end{tabular}

Table 5 Multivariate linear and logistic regression analyses examining the association among sleep-apnea risk and cardiovascular risk factors stratified by group

Notes: ${ }^{*} P<0.05$. a Past or current history or measured blood pressure $\geq 140 / 90 \mathrm{mmHg}$; ${ }^{b}$ ast or current history or fasting glucose $\geq 126 \mathrm{mg} / \mathrm{dL}$. Independent variable: sleepapnea risk (low versus high) assessed by the Berlin Questionnaire. All models included age, BMI, and race as covariates.

Abbreviations: OR, odds ratio; Cl, confidence interval; NFL, National Football League; SBP, systolic blood pressure; DBP, diastolic blood pressure; LDL, low-density lipoprotein; HDL, high-density lipoprotein; CAC, coronary artery calcium. 


\section{Acknowledgments}

Support for FSL was provided by the National Heart, Lung, and Blood Institute (NHLBI; K23HL105887). The Coronary Artery Risk Development in Young Adults (CARDIA) study was supported by contracts HHSN268201300025C, HHSN268201300026C, HHSN268201300027C, HHSN268201300028C, HHSN268201300029C, and HHSN268200900041C from the NHLBI, the Intramural Research Program of the National Institute on Aging (NIA), and an intra-agency agreement between the NIA and NHLBI (AG0005). We would like to thank the Player Care Foundation, which sponsored the data collection from the former NFL players. The authors would also like to thank Dr Stephen Sidney for his contributions to study design and data collection for the CARDIA study and Dr Thomas Allen for his contributions to the National Football League Subcommittee on Cardiovascular Health.

\section{Disclosure}

The authors report no conflicts of interest in this work.

\section{References}

1. Harp JB, Hecht L. Obesity in the National Football League. JAMA. 2005;293:1061-1062.

2. Miller MA, Croft LB, Belanger AR, et al. Prevalence of metabolic syndrome in retired National Football League players. Am J Cardiol. 2008;101:1281-1284.

3. Peppard PE, Young T, Palta M, Dempsey J, Skatrud J. Longitudinal study of moderate weight change and sleep-disordered breathing. JAMA. 2000;284:3015-3021.

4. Zalesin KC, Franklin BA, Miller WM, Peterson ED, McCullough PA. Impact of obesity on cardiovascular disease. Med Clin North Am. 2011;95:919-937.

5. Kahn SE, Hull RL, Utzschneider KM. Mechanisms linking obesity to insulin resistance and type 2 diabetes. Nature. 2006;444:840-846.

6. Peppard PE, Young T, Palta M, Skatrud J. Prospective study of the association between sleep-disordered breathing and hypertension. $N$ Engl J Med. 2000;342:1378-1384.

7. Shahar E, Whitney CW, Redline S, et al. Sleep-disordered breathing and cardiovascular disease: cross-sectional results of the Sleep Heart Health study. Am J Respir Crit Care Med. 2001;163:19-25.

8. Young T, Finn L, Peppard PE, et al. Sleep disordered breathing and mortality: eighteen-year follow-up of the Wisconsin sleep cohort. Sleep. 2008;31:1071-1078.

9. George CF, Kab V, Kab P, Villa JJ, Levy AM. Sleep and breathing in professional football players. Sleep Med. 2003;4:317-325.

10. Rice TB, Dunn RE, Lincoln AE, et al. Sleep-disordered breathing in the National Football League. Sleep. 2010;33:819-824.

Nature and Science of Sleep

\section{Publish your work in this journal}

Nature and Science of Sleep is an international, peer-reviewed, open access journal covering all aspects of sleep science and sleep medicine, including the neurophysiology and functions of sleep, the genetics of sleep, sleep and society, biological rhythms, dreaming, sleep disorders and therapy, and strategies to optimize healthy sleep. The manuscript
11. Albuquerque FN, Kuniyoshi FH, Calvin AD, et al. Sleep-disordered breathing, hypertension, and obesity in retired National Football League players. J Am Coll Cardiol. 2010;56:1432-1433.

12. Friedewald WT, Levy RI, Fredrickson DS. Estimation of the concentration of low-density lipoprotein cholesterol in plasma, without use of the preparative ultracentrifuge. Clin Chem. 1972;18:499-502.

13. Friedman GD, Cutter GR, Donahue RP, et al. CARDIA: study design, recruitment, and some characteristics of the examined subjects. $J$ Clin Epidemiol. 1988;41:1105-1116.

14. Loria CM, Liu K, Lewis CE, et al. Early adult risk factor levels and subsequent coronary artery calcification: the CARDIA study. J Am Coll Cardiol. 2007;49:2013-2020.

15. Netzer NC, Stoohs RA, Netzer CM, Clark K, Strohl KP. Using the Berlin Questionnaire to identify patients at risk for the sleep apnea syndrome. Ann Intern Med. 1999;131:485-491.

16. Agatston AS, Janowitz WR, Hildner FJ, Zusmer NR, Viamonte M, Detrano R. Quantification of coronary artery calcium using ultrafast computed tomography. J Am Coll Cardiol. 1990;15:827-832.

17. Carr JJ, Nelson JC, Wong ND, et al. Calcified coronary artery plaque measurement with cardiac CT in population-based studies: standardized protocol of multi-ethnic study of atherosclerosis (MESA) and coronary artery risk development in young adults (CARDIA) study. Radiology. 2005;234:35-43.

18. Chang AY, FitzGerald SJ, Cannaday J, et al. Cardiovascular risk factors and coronary atherosclerosis in retired National Football League players. Am J Cardiol. 2009;104:805-811.

19. Hurst RT, Burke RF, Wissner E, et al. Incidence of subclinical atherosclerosis as a marker of cardiovascular risk in retired professional football players. Am J Cardiol. 2010;105:1107-1111.

20. Basra SS, Pokharel Y, Hira RS, et al. Relation between playing position and coronary artery calcium scores in retired National Football League players. Am J Cardiol. 2014;114:1836-1840.

21. Luyster FS, Kip KE, Aiyer AN, Reis SE, Strollo PJ. Relation of obstructive sleep apnea to coronary artery calcium in non-obese versus obese men and women aged 45-75 years. Am J Cardiol. 2014;114: 1690-1694.

22. Newman AB, Foster G, Givelber R, Nieto FJ, Redline S, Young T. Progression and regression of sleep-disordered breathing with changes in weight: the Sleep Heart Health study. Arch Intern Med. 2005; 165:2408-2413.

23. Hubert HB, Feinleib M, McNamara PM, Castelli WP. Obesity as an independent risk factor for cardiovascular disease: a 26-year follow-up of participants in the Framingham Heart Study. Circulation. 1983;67:968-977

24. Lee CD, Jacobs DR, Schreiner PJ, Iribarren C, Hankinson A. Abdominal obesity and coronary artery calcification in young adults: the Coronary Artery Risk Development in Young Adults (CARDIA) study. Am J Clinical Nutr. 2007;86:48-54.

25. Blair SN, Church TS. The fitness, obesity, and health equation: is physical activity the common denominator? JAMA. 2004;292:1232-1234.

26. LaMonte MJ, Blair SN. Physical activity, cardiorespiratory fitness, and adiposity: contributions to disease risk. Curr Opin Clin Nutr Metab Care. 2006;9:540-546.

27. Hyman MH, Dang DL, Liu Y. Differences in obesity measures and selected comorbidities in former National Football League professional athletes. J Occup Environ Med. 2012;54:816-819.

management system is completely online and includes a very quick and fair peer-review system, which is all easy to use. Visit http://www. dovepress.com/testimonials.php to read real quotes from published authors. 